\title{
Performance Management and Development System: A Case Study of the Office of the Premier in South Africa
}

\author{
P. K. Manye, D. M. Mello \\ North-West University, Mafikeng Campus, South Africa
}

\begin{abstract}
Public institutions across the globe are confronted with the challenge of achieving more objectives with limited resources. Human resource managers and line managers have even fewer resources to incentivize performance. The limitation in resources makes performance management a difficult task. Top management has performance expectations on the one hand while employees on the other hand expect fair reviews and rewards that are commensurate to their performance from immediate supervisors and their institutions. Despite persistent challenges in the Performance Management and Development System (PMDS), the South African public service has not initiated internal surveys to establish perceptions of employees regarding the system. In such instances, the employer assumes that employees are happy or utilizes the number of grievances lodged as a benchmark for effective implementation of PMDS. This study closes the gap between what the employer thinks and the real perception of employees at operational level.
\end{abstract}

Keywords: performance, assessment, management, development, South Africa

The perceptions of employees regarding performance management and its effectiveness need to be assessed regularly to ensure that PMDS (Performance Management and Development System) still meets the primary objectives that it was established for. This paper represents an attempt, albeit at a smaller scale, to assess the effectiveness of the PMDS. A questionnaire was used to establish the perceptions of officials of the Office of the Premier who are assessed annually according to the current PMDS. This paper outlines the method followed in conducting the research, presents and analyzes data, discusses results, outlines main findings, and makes recommendations.

\section{Research Method}

The research method is a careful planning of operations to be followed in collecting the data in a rigorous, systematic way, in accordance with methods and ethics of social research. There are several types of research designs used for research purposes. The critical part in any study is to choose the most appropriate design. Creswell (2013, p. 12) emphasized this by stating that the researcher not only selects qualitative, quantitative, or mixed methods of the study she/he conducts; the researcher also needs to critically decide on a type of study within these three choices. Creswell's statement is corroborated by Brynard and Hanekom (2006, p. 38) who

P. K. Manye, BAdmin Hons, North-West University, Mafikeng Campus, South Africa; research fields: public administration, performance management.

Corresponding author: D. M. Mello, DAdmin, North-West University, Mafikeng Campus, South Africa; research fields: public administration, monitoring and evaluation of performance. 
are of the view that the researcher chooses either of the designs or uses mixed designs for better insight into the research area. Research designs have three types of inquiry, namely qualitative, quantitative, and mixed methods approaches, and they provide specific path for procedures in a research design (Creswell 2013, p. 13). The quantitative strategy was followed in the process of data collection and data analysis to explore the implementation of PMDS. In this study, a questionnaire was used to collect data.

\section{Population and Sample}

\section{Population}

Newman (2004, p. 205) defined population as a gathering of people of specified categories possessing a characterized space at a specific time or an aggregate gathering of life forms of the same species (or different gatherings inside of people may trade hereditary data). Population incorporates the total collection of all units of analysis about which the researcher wishes to draw specific conclusion from their study (Welman, Kruger, \& Mitchel 2005, p. 52). Population can thus be said to be a group of potential participants to whom the researcher wants to generalize the results of a study. In this study, the population consists of employees in the Office of the Premier in South Africa. Johnson and Christensen (2010, p. 257) affirmed that a target population is the bigger populace to whom the research study results are to sum up. For the purpose of this investigation, a sample was drawn from the Office of the Premier which had a total of 748 employees at the time the research was conducted. All these employees constituted the population of the study.

\section{Sampling}

Daniel (2011, p. 1) defined sampling as the selection of a subset of the members of a population for inclusion in a study. Antonius (2003, p. 108) defined a sampling design as a detailed plan for arriving at a sample. Sampling design is specific about the type of sample used, and mentions the units from which the sample is selected, the number of units necessary, and the precise method of selecting them. A sample is regarded as a small number of individuals whom the researcher picks from the main group for the purpose of the study they are conducting. Bryman (2008, p. 187) defined a sample as segment of a population that is carefully chosen for research purposes.

A sample of 90 participants was selected for this study. The 90 participants constitute $12 \%$ of the total population. Not all questionnaires were returned. Questionnaires that were returned were fully completed, and identities of individuals who filled out questionnaires were kept confidential. The population for this study comprised of employees ranging from senior management, middle management, and subordinate staff. There are mainly two types of sampling, Antonius (2003, p. 109) stated that they are namely: probabilistic samples and non-probabilistic samples. For the purposes of this research undertaking, the simple random sampling method was employed.

\section{Questionnaires}

In all cases, the central part of any questionnaire is to give a standard for all subjects. Questionnaires ensure that when questions are asked, there is consistency (Brace, 2013, p. 4). Structured questionnaires were handed out to employees in the Office of the Premier, which had only one open-ended question. A spread sheet programme was used to analyze 90 questionnaires collected out of 105 that were initially distributed to employees in the Office of the Premier. The results of 90 questionnaires are presented in charts and tables that appear below. 


\section{Presentation and Analysis of Data}

In this section, data which were gathered through questionnaires are presented.

\section{Biographical Data}

Table 1 below represents gender distribution and indicates that from the questionnaires received, the sample had more females (56\%) than males who are $44 \%$ of the sample. This means that there are more females employed in the Office of the Premier. These figures are a sign that the Office of the Premier has some success in the implementation of the Employment Equity Act of 1998.

Table 1

Gender Description of Participants

\begin{tabular}{lll}
\hline Gender & Frequency & Percentage \\
\hline Female & 50 & $56 \%$ \\
Male & 40 & $44 \%$ \\
Total & 90 & $100 \%$ \\
\hline
\end{tabular}

Table 2 below gives an illustration of age distribution of the sample. The findings from the sample show that most of the respondents who are employed in the Office of the Premier are between the age of 35 and 43 years, followed by those who are in the age range of 25 to 34 years, and the least being in the range between 18 and 24 years. It can be observed that employees in the age range 35-43 are almost twice the number of those in the age range 18-24.

Table 2

Age Description of Participants

\begin{tabular}{lll}
\hline Age range & Frequency & Percentage \\
\hline $18-24$ years & 14 & $16 \%$ \\
$25-34$ years & 27 & $30 \%$ \\
$35-43$ years & 32 & $35 \%$ \\
$44+$ years & 17 & $19 \%$ \\
Total & 90 & $100 \%$ \\
\hline
\end{tabular}

Table 3

Distribution in Terms of Race

\begin{tabular}{lll}
\hline Race & Frequency & Percentage \\
\hline Black & 83 & $92 \%$ \\
Coloured & 4 & $5 \%$ \\
Indian & 0 & $0 \%$ \\
White & 3 & $3 \%$ \\
Other & 0 & $0 \%$ \\
Total & 90 & $100 \%$ \\
\hline
\end{tabular}

Table 3 shows the distribution of race in the sample. Most of the people who are employed in the Office of the Premier according to the sample are black (92\%). The sample collected shows that there is not a single Indian employee represented in the sample and only 5\% are coloured employees as well as $3 \%$ are white employees. The figures presented in Table 3 are closer to the demographics of the province. These figures do not in any way suggest that the province does not have Indian people. Black people are more in the sample 
because of the high number of black residents in the area of study. These figures suggest that the Office of the Premier may have to consider hiring more Indian people in proportion to the provincial demographics.

Table 4 below indicates that $79 \%$ of the employees in the sample are permanently employed, followed by interns who constitute $18 \%$ of sample and only $3 \%$ of employees are on contract. From the sample, it can be observed that there are a high number of interns as opposed to contract workers.

Table 4

Type of Contract

\begin{tabular}{lll}
\hline Type of contract & Frequency & Percentage \\
\hline Permanent & 71 & $79 \%$ \\
Intern & 16 & $18 \%$ \\
Contract & 3 & $3 \%$ \\
Total & 90 & $100 \%$ \\
\hline
\end{tabular}

\section{Employee Performance and Development}

Section B of the questionnaire encompasses employee performance and development. This section tries to establish whether employees are motivated by their managers to develop and do more in relation to PMDS.

Table 5 indicates that $32.22 \%$ of the respondents agreed that there are incentives put in place to make them perform better, while the smallest portion of the sample (7.78\%) strongly disagreed. This could be that employees do not have any incentives put in place for them to perform better. The sample further points out that $26.67 \%$ were neutral, $17.78 \%$ disagreed, and $15.56 \%$ strongly agreed.

Table 5

Question 1: There Are Incentives Put in Place to Motivate Me to Perform Well

\begin{tabular}{ll}
\hline Variable & Percentage of responses \\
\hline Strongly disagree & $7.78 \%$ \\
Disagree & $17.78 \%$ \\
Neutral & $26.67 \%$ \\
Agree & $32.22 \%$ \\
Strongly agree & $15.56 \%$ \\
\hline
\end{tabular}

Table 6 below demonstrates that the majority of the sample (43.33\%) agreed that they are assessed based on the criteria agreed upon by them and their supervisors, while a small fraction disagreed (5.56\%). The 38.89\% strongly agreed, $2.22 \%$ strongly disagreed, and the rest of the respondents $(10 \%)$ were not quite sure and decided to be neutral. The reason for this could be the number of interns employed in the Office of the Premier. Interns serve for a period of one year and may not have the full knowledge of PMDS.

Table 6

Question 2: I Am Assessed Based on Criteria Agreed Upon Between Myself and the Supervisor

\begin{tabular}{ll}
\hline Variable & Percentage of responses \\
\hline Strongly disagree & $2.22 \%$ \\
Disagree & $5.56 \%$ \\
Neutral & $10.00 \%$ \\
Agree & $43.33 \%$ \\
Strongly agree & $38.89 \%$ \\
\hline
\end{tabular}


Table 7 indicates that majority of the respondents in the sample (46\%) agreed that their work is evaluated as per work agreement, followed by $36 \%$ of the respondents who strongly agreed. This could be that such respondents are well aware of what is expected of them and is developed in relation to PMDS and how it is implemented in the Office of the Premier. The rest of the responses were spread amongst those who were neutral (10\%), disagreed (5\%), and strongly disagreed (3\%).

Table 7

Question 3: My Work Is Evaluated as per Work Agreement

\begin{tabular}{ll}
\hline Variable & Percentage of responses \\
\hline Strongly disagree & $3 \%$ \\
Disagree & $5 \%$ \\
Neutral & $10 \%$ \\
Agree & $46 \%$ \\
Strongly agree & $36 \%$ \\
\hline
\end{tabular}

Of the sample collected based on Table 8, the majority of respondents who constitute $42.22 \%$ agreed that their managers positively influence their performance, while the smallest fraction of the sample $6.67 \%$ strongly disagreed. The reason could be that some employees do not have good working relations with their managers.

Table 8

Question 4: My Manager Influences My Performance Positively

\begin{tabular}{ll}
\hline Variable & Percentage of responses \\
\hline Strongly disagree & $6.67 \%$ \\
Disagree & $8.89 \%$ \\
Neutral & $24.44 \%$ \\
Agree & $42.22 \%$ \\
Strongly agree & $17.78 \%$ \\
\hline
\end{tabular}

Table 9 illustrates the number of employees who find their job to be stimulating. The majority of respondents (37.78\%) agreed that they find their job to be stimulating, while $24.44 \%$ strongly agreed. These are employees who are fairly happy with the work they do and are able to go an extra mile in their work. This sample also encompasses a small portion of $2.22 \%$ of employees who strongly disagreed, while $27.78 \%$ were neutral and $7.78 \%$ disagreed.

Table 9

Question 5: I Find My Job to Be Stimulating

\begin{tabular}{ll}
\hline Variable & Percentage of responses \\
\hline Strongly disagree & $2.22 \%$ \\
Disagree & $7.78 \%$ \\
Neutral & $27.78 \%$ \\
Agree & $37.78 \%$ \\
Strongly agree & $24.44 \%$ \\
\hline
\end{tabular}

From Table 10, it is evident that the majority of respondents were neutral $(40 \%)$. This might be because they are not sure whether there is sufficient action taken to improve their performance, and they have probably been doing the same work for years and feeling that they have not been developed sufficiently. Employees who 
were neutral were followed by $28 \%$ who agreed that there is sufficient action taken towards improving their performance. The rest of the respondents were divided into $7 \%$ who strongly disagreed, $15 \%$ who disagreed, and $10 \%$ who strongly agreed.

Table 10

Question 6: There Is Sufficient Action Taken to Improve My Performance

\begin{tabular}{ll}
\hline Variable & Percentage of responses \\
\hline Strongly disagree & $7 \%$ \\
Disagree & $15 \%$ \\
Neutral & $40 \%$ \\
Agree & $28 \%$ \\
Strongly agree & $10 \%$ \\
\hline
\end{tabular}

Table 11 indicates that of the sample drawn, a large number (31\%) indicated that they agree that the current performance management is effective, meaning that they are happy with it and are seeing best results. Those who strongly agree were $12 \%$. The rest of the respondents were spread amongst $8 \%$ strongly disagreed, $29 \%$ neutral, and $20 \%$ disagreed. In a related study conducted by Makamu (2016, p. 254), $60.2 \%$ of respondents drawn from a sample of national government departments agree that the system is effective. The $74.1 \%$ in the same study pointed out that there are challenges in the implementation of the performance management system in South Africa.

Table 11

Question 7: The Current Performance Management and Development System Is Effective

\begin{tabular}{ll}
\hline Variable & Percentage of responses \\
\hline Strongly disagree & $8 \%$ \\
Disagree & $20 \%$ \\
Neutral & $29 \%$ \\
Agree & $31 \%$ \\
Strongly agree & $12 \%$ \\
\hline
\end{tabular}

\section{Employee Performance Assessment and Development}

Section $\mathrm{C}$ of the questionnaire evaluates employee assessment and development.

Table 12 illustrates that all the participants (100\%) understand the work they do. The researchers have established that although employees might encounter problems in the work they do, they fairly understand it, and they just need development.

Table 12

Question 8: I Understand the Work I Do

\begin{tabular}{ll}
\hline Variable & Percentage of respondents \\
\hline Yes & $100 \%$ \\
No & $0 \%$ \\
\hline
\end{tabular}

Table 13 indicates that $89 \%$ of the sample agreed that they have performance objectives that are within their control. The reason might be that most employees agree with their managers about what they intend on achieving. The rest of the respondents disagreed (11\%). The $11 \%$ who disagreed may represent employees whose performance objectives are either dictated by supervisors or they are non-existent. 
Table 13

Question 9: I Have Performance Objectives That Are Within My Control

\begin{tabular}{ll}
\hline Variable & Percentage of respondents \\
\hline Yes & $89 \%$ \\
No & $11 \%$ \\
\hline
\end{tabular}

Table 14 shows that $60 \%$ of the participants agreed that they get beneficial feedback, while $40 \%$ disagreed. The $40 \%$ who disagreed to get beneficial feedback may be underperforming employees who often get negative feedback based on unsatisfactory performance.

Table 14

Question 10: I Receive Beneficial Feedback on My Performance

\begin{tabular}{ll}
\hline Variable & Percentage of respondents \\
\hline Yes & $60 \%$ \\
No & $40 \%$ \\
\hline
\end{tabular}

As illustrated in Table 15 below, $31 \%$ of the respondents said no to that there are opportunities for them to develop their skills. The rest of the sample agreed (69\%). These could be that individuals are well developed and well suited to benefit from PMDS.

Table 15

Question 11: There Are Opportunities for Me to Develop My Skills

\begin{tabular}{ll}
\hline Variable & Percentage of respondents \\
\hline Yes & $69 \%$ \\
No & $31 \%$ \\
\hline
\end{tabular}

Table 16 indicates that $48 \%$ of the respondents were not satisfied with opportunities available for them to develop their careers, while $52 \%$ agreed. For those who disagreed, it could be that they still need more training to develop and like the work they do.

Table 16

Question 12: I Am Satisfied With Opportunities Available for Career Development

\begin{tabular}{ll} 
Variable & Percentage of respondents \\
\hline Yes & $52 \%$ \\
No & $48 \%$ \\
\hline
\end{tabular}

Table 17 indicates the percentage of employees who are always motivated to attend development programmes. The figures show that of the 90 respondents, $73 \%$ agreed that they are always looking forward to attending development programmes while the $27 \%$ disagreed.

Table 17

Question 13: I Am Always Motivated to Attend Development Programmes

\begin{tabular}{ll}
\hline Variable & Percentage of respondents \\
\hline Yes & $73 \%$ \\
No & $27 \%$ \\
\hline
\end{tabular}

As illustrated in Table 18 below, $72 \%$ of participants in the study indicated that they are satisfied with the manner in which their performance is assessed; the reason could be that they fully know what is expected of 
them, or the other reason could be that they are motivated to do more. The rest of the sample (28\%) disagreed.

Table 18

Question 14: I Am Satisfied With the Assessment of My Performance

\begin{tabular}{ll}
\hline Variable & Percentage of respondents \\
\hline Yes & $72 \%$ \\
No & $28 \%$ \\
\hline
\end{tabular}

As illustrated in Table 19, 59\% of the respondents agreed that they have attended PMDS training, while the remaining $41 \%$ disagreed. Most of the respondents who disagreed (41\%), as observed, may be interns and newly appointed officials in the public service.

Table 19

Question 15: Have You Attended Any PMDS Workshop or Training

\begin{tabular}{ll}
\hline Variable & Percentage of respondents \\
\hline Yes & $59 \%$ \\
No & $41 \%$ \\
\hline
\end{tabular}

\section{Open-Ended Question}

The questionnaires handed out to employees for the sample had only one open-ended question. Responses to this question were categorized accordingly, coded into numerical data descriptions, and analyzed accordingly. These responses are presented in a bar graph below.

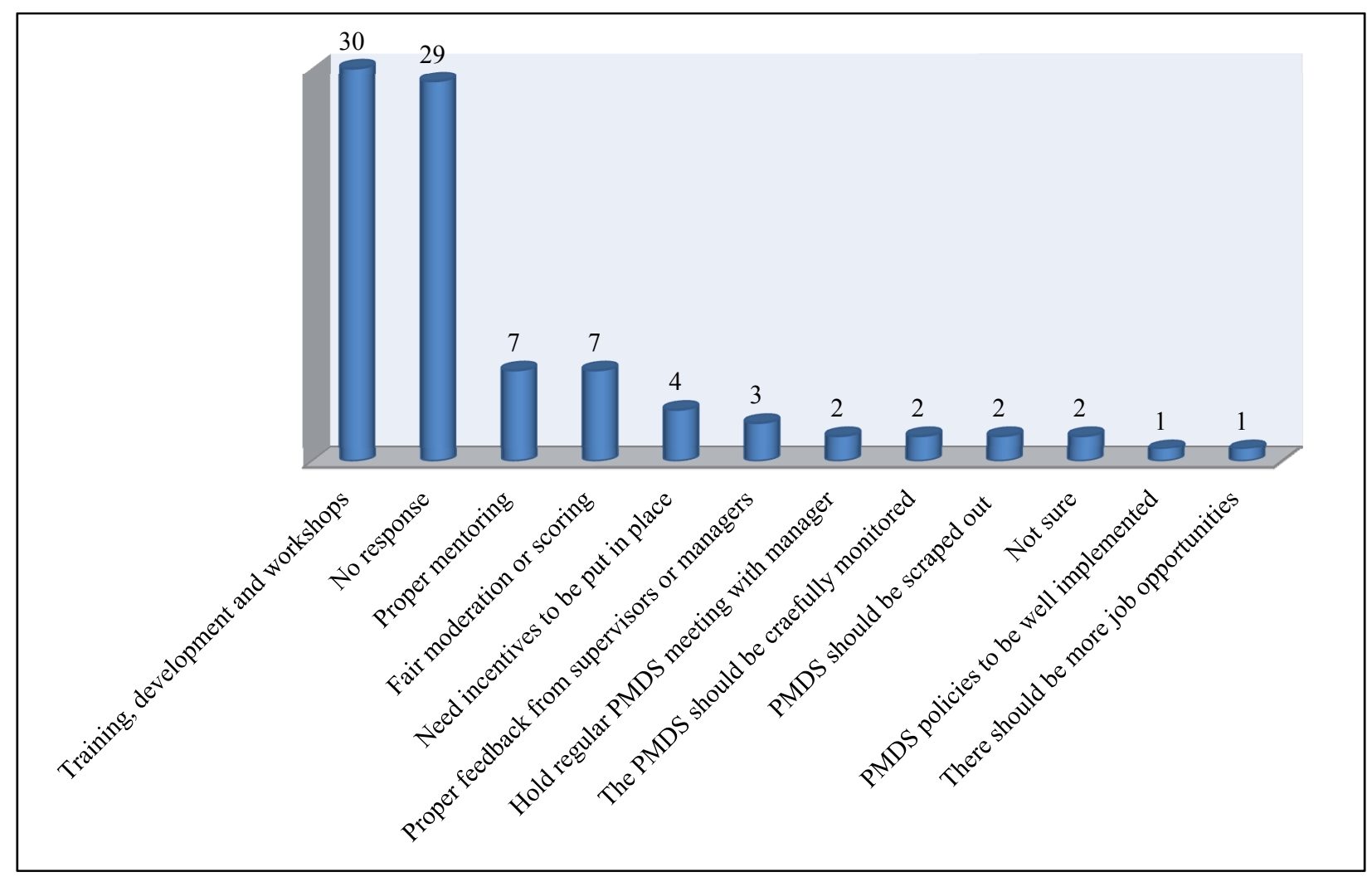

Figure 1. Question 16: What can be done to improve PMDS and your individual performance. 
Figure 1 above is an illustration of how the sample responded to the open-ended question. The responses were analyzed under relevant themes. From the graph, the majority which was 30 respondents wanted to attend more training and workshops and need development. The reason for this might be that individuals want to learn and develop more in relation to the work they do. Seven of the respondents wanted fair scoring or moderation on their performance, while the other seven said they wanted proper mentoring by their managers. Four respondents from the sample stated that they needed incentives to be put in place. Of the sample drawn, 29 did not write anything or just "N/A".

\section{Findings and Discussion of Results}

The researchers find the following in relation to the main research questions posed:

\section{Are There Incentives to Motivate Employees}

Questions 1, 11, and 15 of the questionnaire attempted to determine what the sample drawn thought about the abovementioned statement. Many of the respondents in relation to the data analyzed agreed to these questions. In the data analyses with regard to question 1,32.22\% of the sample agreed that they have incentives put in place. This explains why just a few of the respondents strongly agreed. These are employees who need to be more informed of the incentives put in place provided they perform according to set standards. Question 11 also relates to the above statement, where $69 \%$ of the respondents agreed. This could be because these employees are well aware of which incentives are there and are satisfied, although the $31 \%$ need to be motivated more to take opportunities available to make use of incentives. Lastly, question 15 indicates that $59 \%$ of the respondents agreed that they have attended PMDS training; the rest of the sample disagreed. These are employees who need to attend training for them to be equipped with more PMDS knowledge.

\section{What Is the Extent of Objectivity in the Appraisal of Employees}

Questions 5, 7, 8, and 9 of the questionnaire were put in place to establish whether there is fairness in how employees are appraised. Question 5 was set to determine whether employees find their work stimulating, where only $2.22 \%$ of respondents strongly disagreed. These employees need to be guided by supervisors to find ways of making their job stimulating. Question 7 tried to establish whether the current PMDS is effective. Out of the sample drawn, $31 \%$ agreed, followed by $29 \%$ respondents who remained neutral. The $20 \%$ of the respondents disagreed; these included those respondents who said PMDS should be scrapped in the open-ended question. Question 8 reflected on whether or not employees understand their work. All 90 respondents said yes. Lastly, question 9 tried to establish whether employees have performance objectives that are within their control. From the sample used, $89 \%$ respondents said yes, while $11 \%$ respondents said no.

\section{How Often Performance Is Evaluated}

Questions 3 and 14 tried to establish how often employee performance is evaluated. In question 3, 46\% of the respondents agreed that their work is evaluated as per their work plan, while $3 \%$ strongly disagreed. This shows that the department needs to put more time in ensuring that the $3 \%$ should be more informed to satisfy their work needs. Question 14 showed that over $50 \%$ of participants are satisfied with how they are assessed.

\section{How Does the Role of Management Influence Employee Performance}

Questions 2, 4, and 13 tried to establish how much impact the role of managers has on the performance of employees. Question 2 being the core area relating to this study established that majority of respondents agreed that they are assessed based on the criteria agreed upon by their supervisors and them. Only $2.22 \%$ strongly 
disagreed, and the reason could be that there is no clear communication between employee and supervisor. Question 4 on the other hand tried to evaluate whether managers influence performance of employees positively. The $17.78 \%$ strongly agreed and $6.67 \%$ strongly disagreed. This indicates that supervisors and employees need to establish clear working relations. Lastly, question 13 established whether employees are motivated to attend development programmes. Motivation in the workplace is mostly developed by supervisors and managers. Out of 90 respondents, $73 \%$ agreed that they are motivated to attend more development programmes, and this shows that employees are eager to learn more about PMDS.

\section{Is There Sufficient Action Taken to Improve Performance Appraisal}

Questions 6,10,12, and 16 attempted to discover whether there is sufficient action taken to improve personal performance of employees. Question 6 probed whether sufficient action is taken to improve individual performance of employees. From the respondents, the majority (40\%) ticked neutral. The reason for this might be due to lack of communication between supervisor and employee, or even time constraints. Question 10 stated that I receive beneficial feedback on my performance. The $60 \%$ of the respondents agreed that they get beneficial feedback, while $40 \%$ disagreed. Many employees find it motivating to receive beneficial feedback from their supervisor on their work. This gives them motivation to do more and achieve greater standards. Question 12 established that employees are satisfied with opportunities available to develop their careers. Out of the 90 participants, $52 \%$ agreed that they are satisfied, while $48 \%$ disagreed. The reason for this might be that employees are not happy with the work they do.

Lastly, question 16 was an open-ended question which tried to establish what can be done to improve PMDS in the department. Many respondents (30) stated that they needed more training, which is what the department needs to put in place. Seven respondents stated that they needed fair scoring or moderation. Many employees do not get fair scoring due to the fact that supervisors give them a low score for them not to get a performance bonus. The other reason could be a huge workload that does not allow employees to do all their work on time. This can be circumvented by setting targets or standards that are within the employees' control for them to perform better.

\section{Conclusions and Recommendations}

(1) With regard to training, the Office of the Premier needs to come up with a survey to establish which employees need PMDS training;

(2) Newly appointed managers and employees should undergo PMDS training within 30 days after they have been employed into the Office;

(3) Employees should be given a chance to voice out their opinion with regard to being assessed; this will assist with knowing which areas need improvement for better performance in the long run;

(4) PMDS workshops should include assessment instruments to provide both employees and managers with the opportunity for them to assess themselves for all training they have attended;

(5) After concluding PMDS training, the Office of the Premier should ensure that employees understand how their individual performance impacts the overall productivity, through regular assessments;

(6) To ensure that compliance is strengthened, performance submissions should be done timeously;

(7) Interns should attend training so as to better their understanding of PMDS in the public service in case they get permanently employed. This will help them better their understanding of the system and also allow them to develop their careers in the public sector. 


\section{References}

Antonius, R. (2003). Interpreting quantitative data with SPSS. London: Sage Publishers.

Brace, B. (2013). Questionnaire design: How to plan, structure and write survey material for effective market research. Britain: Kogan Page Publishers.

Bryman, A. (2008). Social research methods (3rd ed.). Cape Town: Oxford University Press.

Brynard, P. A., \& Hanekom, S. X. (2006). Introduction to research in management related fields (2nd ed.). Pretoria: Van Schaik Publishers.

Creswell, J. (2013). Research design: Qualitative, quantitative, and mixed methods approaches. New York: Sage Publications.

Daniel, J. (2011). Sampling essentials: Practice guidelines for making sampling. United States of America: Sage Publishers.

Johnson, B., \& Christensen, L. (2010). Educational research: Qualitative, quantitative, and mixed method. United States of America: Sage Publishers.

Makamu, N. I. (2016). Assessment of performance management and development system in selected South African national government departments. Unpublished thesis, North-West University, Mafikeng, South Africa.

Newman, M, C. (2004). Quantitative methods in aquatic ecotoxicology. United States of America: CRP Press.

Welman, J. C., Kruger, S. J., \& Mitchel, B. C. (2005). Research methodology (3rd ed.). Cape Town: Oxford University Press. 